JOURNAL OF SYNCHROTRON RADIATION

ISSN 1600-5775

Received 3 September 2021

Accepted 30 November 2021

Edited by M. Wang, Paul Scherrer Institute, Switzerland

Keywords: $\mathrm{CuCrZr}$; tungsten inert gas welding (TIG); electron beam welding (EBW); finiteelement analysis (FEA); high-heat-load photon absorber.

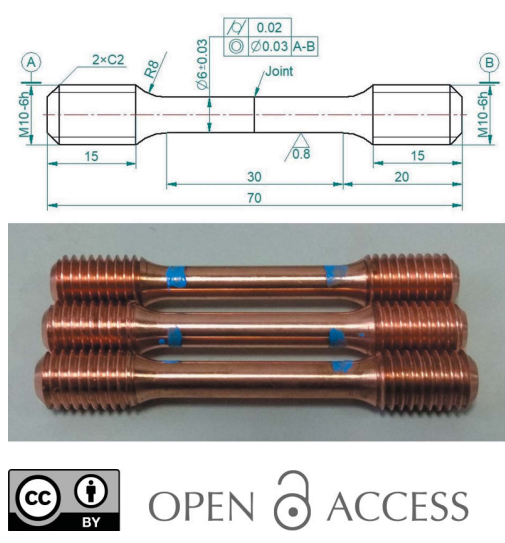

\section{Vacuum joints of CuCrZr alloy for high-heat-load photon absorber}

\author{
Yongjun Li,* Limin Jin, Wanqian Zhu,* Song Xue, Min Zhang and Shuai Wu
}

Shanghai Synchrotron Radiation Facility, Zhangjiang Laboratory, Shanghai Advanced Research Institute, Chinese Academy of Sciences, Shanghai 201204, People's Republic of China. *Correspondence e-mail: liyj77@163.com, zhuwanqian@zjlab.org.cn

A photon absorber, as a critical component of a synchrotron front-end, is mainly used to handle high-heat-load synchrotron radiation. It is mostly made of dispersion strengthened copper or $\mathrm{CuCrZr}$ which can retain high performance at elevated temperatures. Joining processes for vacuum, including tungsten inert gas welding (TIG) and electron beam welding (EBW), are novel ways to make a long photon absorber from two short ones and reduce power density. The mechanical properties of TIG joints and EBW joints of $\mathrm{CuCrZr}$ to the same material are obtained by tensile tests at $20^{\circ} \mathrm{C}, 100^{\circ} \mathrm{C}, 200^{\circ} \mathrm{C}, 300^{\circ} \mathrm{C}$ and $400^{\circ} \mathrm{C}$. Testing results indicate that the tensile strength and yield strength of both vacuum joints decline as temperature increases. Compared with TIG joints, EBW joints have higher strength, better ductility and a more stable performance. An engineering conservative acceptance criteria of the vacuum joints is created by the polynomial fitting method. A novel welded photon absorber with a total length of $600 \mathrm{~mm}$ has been successfully designed and manufactured. Finite-element analysis by ANSYS shows that the maximum temperature, equivalent stress and strain are only $31.5 \%, 36.2 \%$ and $1.3 \%$, respectively, of the corresponding thresholds. The welded photon absorbers with EBW joints will be applicable in the highest-heat-load front-end in the Shanghai Synchrotron Radiation Facility Phase-II beamline project.

\section{Introduction}

Shanghai Synchrotron Radiation Facility (SSRF) is an advanced third-generation synchrotron radiation light source consisting of a $150 \mathrm{MeV}$ electron linear accelerator, a full energy booster and a $3.5 \mathrm{GeV}$ storage ring ( He \& Zhao, 2014; Zhao et al., 2013). Insertion devices, including undulators and wigglers, are always employed to generate high-quality synchrotron light. The power output of an insertion device is up to several tens of kilowatts and its peak power density can be larger than $100 \mathrm{~kW} \operatorname{mrad}^{-2}$. The photon absorber, as a critical component of a synchrotron front-end, is an ultrahighvacuum unit primarily for handling the high heat load from insertion devices or bending magnets (Sakurai et al., 1998; Shu \& Ramanathan, 2002). High-heat-load photon absorbers are mostly made of dispersion strengthened copper or $\mathrm{CuCrZr}$ alloy at SSRF and many other synchrotron radiation facilities. However, due to the technical requirements of high-dimensional accuracy and the low surface roughness of photon absorbers, only short ones whose lengths are no more than $300 \mathrm{~mm}$ could be made by low-speed wire-cut electrical discharge machining in China, which were widely used in the SSRF Phase-I project. Joining processes for vacuum, including tungsten inert gas welding (TIG) and electron beam welding (EBW), are novel ways to make a longer photon absorber by joining two shorter ones and to reduce power density. 
Table 1

Physical properties of CuCrZr and Glidcop ${ }^{\circledR}$ AL-15.

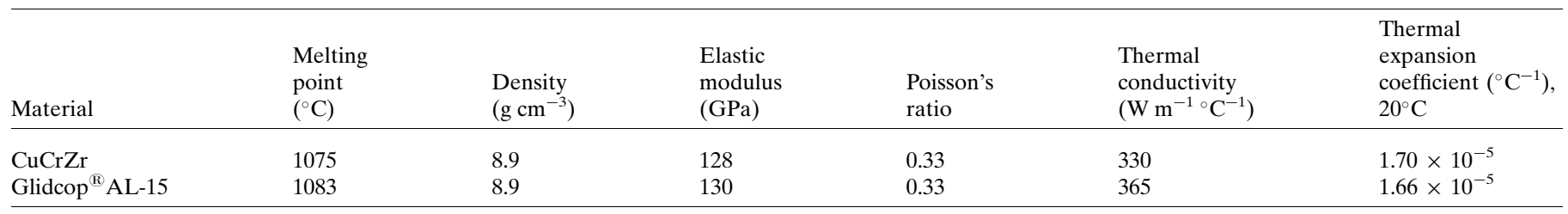

Table 2

Mechanical properties of $\mathrm{CuCrZr}$ and Glidcop ${ }^{\mathbb{R}} \mathrm{AL}-15$.

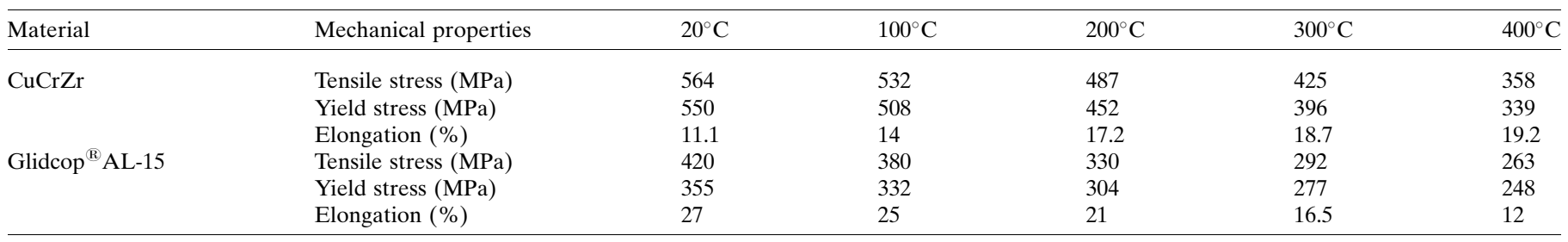

$\mathrm{CuCrZr}$, as a precipitation hardening copper alloy with excellent thermal conductivity, strength retention, good ductility and microstructural stability at elevated temperatures, developed in recent years, is widely applied in aerospace, fusion application, synchrotron radiation etc. (Huang et al., 2019; Shueh et al., 2017; Zinkle, 2016). Compared with dispersion strengthened copper, $\mathrm{CuCrZr}$ alloy is much cheaper and available even in our local supply vendors in China (Jin et al., 2021; Sheng et al., 2016). Extensive studies on the mechanical properties of $\mathrm{CuCrZr}$ alloy have been conducted (DeGroh et al., 2008; Edwards et al., 2007; Nomura et al., 2002). Performances of the joints of $\mathrm{CuCrZr}$ alloy to other alloys have also been studied by various groups (Gillia et al., 2009; Sahlot et al., 2018; Wei et al., 2018).

In this paper, to meet the project requirements, $\mathrm{CuCrZr}$ was chosen to make tensile specimens by TIG and EBW. The mechanical properties of the vacuum joints of $\mathrm{CuCrZr}$ to the same material at $20^{\circ} \mathrm{C}, 100^{\circ} \mathrm{C}, 200^{\circ} \mathrm{C}, 300^{\circ} \mathrm{C}$ and $400^{\circ} \mathrm{C}$ were obtained by tensile tests. An engineering conservative acceptance criteria of the vacuum joints is created by the polynomial fitting method. A novel high-heat-load photon absorber with a total length of $600 \mathrm{~mm}$ has been successfully designed and manufactured. Finite-element analysis by $A N S Y S$ shows that the maximum temperature, equivalent stress and strain on the EBW joint of the photon absorber are much lower than the corresponding thresholds, which illustrates that welded photon absorbers will be applicable in the highest-heat-load front-end in the SSRF Phase-II beamline project.

\section{Experimental procedures}

\subsection{Material}

$\mathrm{CuCrZr}$ is a precipitation hardened alloy with about $0.5-$ $1.5 \%$ chrome and $0.05-0.25 \%$ zirconium. Glidcop ${ }^{\circledR}$ AL- 15 , a kind of $\mathrm{Al}_{2} \mathrm{O}_{3}$ dispersion strengthened copper produced by North American Höganäs High Alloys LLC in the USA, was utilized in the SSRF Phase-I front-end. Table 1 shows the physical properties of $\mathrm{CuCrZr}$ and Glidcop ${ }^{\circledR} \mathrm{AL}-15$ at $20^{\circ} \mathrm{C}$. The mechanical properties of $\mathrm{CuCrZr}$ and Glidcop ${ }^{\circledR} \mathrm{AL}-15$ at different temperatures are shown in Table 2 (DeGroh et al., 2008; Glidcop ${ }^{\mathbb{R}}$, 2021). Compared with Glidcop ${ }^{\mathbb{}}$ AL-15, the elongation of $\mathrm{CuCrZr}$ is worse at some temperatures, while the tensile stress and yield stress of $\mathrm{CuCrZr}$ are much better at all listed temperatures. In this paper, $\mathrm{CuCrZr}$ was chosen to make tensile specimens.

\subsection{Welding technology}

TIG welding is the most versatile welding process employed in vacuum fields where a high degree of quality and accuracy is required (Manohar et al., 2018). A welding speed of $50 \mathrm{~mm} \mathrm{~min}{ }^{-1}$ and a gas flow of $9 \mathrm{~L} \mathrm{~min}^{-1}$ were chosen to join two pieces of $\mathrm{CuCrZr}$ specimens using an WSE-500 argon arc welder. The test welding is done by keeping voltage at about $15 \mathrm{~V}$ and current at about $160 \mathrm{~A}$ throughout the welding process.

EBW is a fusion welding process under vacuum as it is of high energy density, low heat input and rapid cooling rate (Zeng, 1993). An EBW700 electron beam welder was employed in the experiment and pumped to a vacuum degree of $4.5 \times 10^{-3} \mathrm{~Pa}$. A voltage of $150 \mathrm{kV}$ and a beam current of $9 \mathrm{~mA}$ were precisely controlled to produce a beam of highvelocity electrons. With a welding speed of $10 \mathrm{~mm} \mathrm{~s}^{-1}$, two pieces of $\mathrm{CuCrZr}$ specimens melted and flowed together on the joint.

\subsection{Testing procedures}

After welding, tensile specimens were machined according to GB/T 2651-2008 (ISO 4136: 2001, IDT), as shown in Fig. 1. Tensile tests at room temperature were conducted using a Zwick Z100TEW electronic universal testing machine based on GB/T 228.1-2010 (ISO 6892-1: 2009, MOD); a Zwick Z250 electronic universal testing machine was used at elevated 

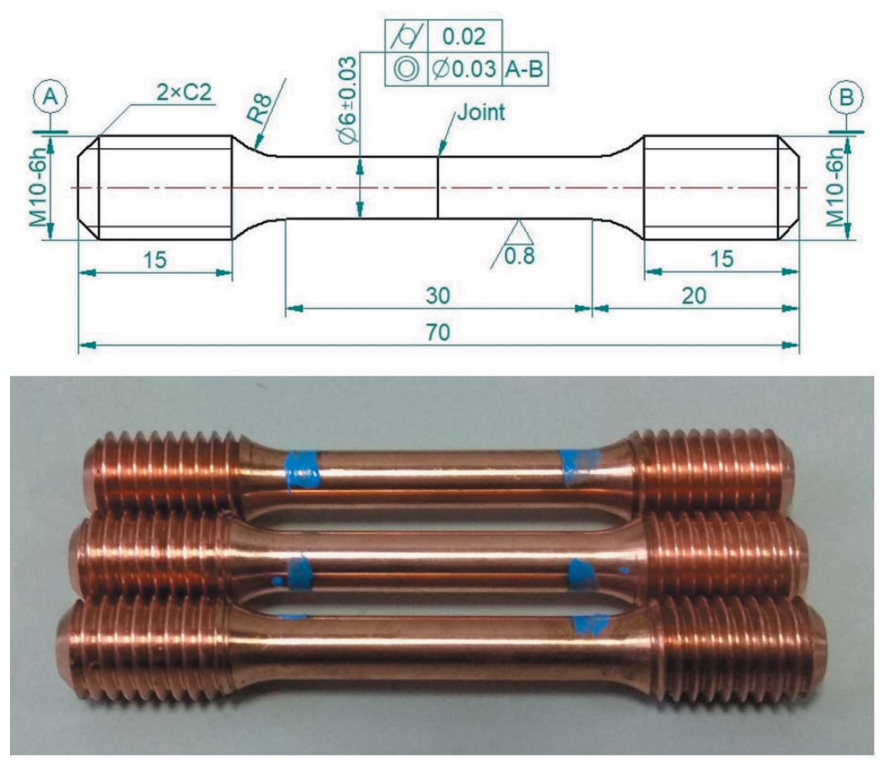

Figure 1

Tensile specimen (units: $\mathrm{mm}$ ).

temperatures adopting GB/T 4338-2006 (ISO 783: 1999, MOD).

\section{Results and discussions}

\subsection{Testing results of TIG joints}

Thirty TIG tensile specimens were separated into five groups randomly and mechanical properties at five different temperatures were obtained. The results are shown in Tables 3, 4 and 5 , where $A$ is elongation after fracture, $\bar{A}$ is the mean of $A, A_{\mathrm{s}}=\left[\sum_{i=1}^{6}\left(A_{i}-\bar{A}\right)^{2} / 5\right]^{1 / 2}(i=1-6)$ is the standard deviation of $A$ by the Bessel formula; $R_{\mathrm{m}}$ is the tensile strength, $\overline{R_{\mathrm{m}}}$ is the mean of $R_{\mathrm{m}}, R_{\mathrm{ms}}$ is the standard deviation of $R_{\mathrm{m}} ; R_{\mathrm{p}}$ is the yield strength, $\overline{R_{\mathrm{p}}}$ is the mean of $R_{\mathrm{p}}$, and $R_{\mathrm{ps}}$ is the standard deviation of $R_{\mathrm{p}}$. Fracture surfaces of all specimens occurred on the joints.

All TIG joints have yielding processes with poor consistency, demonstrating that TIG joints have poor ductility. From $\overline{R_{\mathrm{m}}}$ and $\overline{R_{\mathrm{p}}}$, tensile strength and yield strength decline with the rising of temperature. Meanwhile, tensile strengths and yield strengths vary a lot at the same temperature. Take the tensile strength at $400^{\circ} \mathrm{C}$, for example: the maximum is nearly four times the minimum, and the biggest standard deviation is $38.2 \mathrm{MPa}$, which is even larger than half of $\overline{R_{\mathrm{m}}}$ at $400^{\circ} \mathrm{C}$. It is indicated that the TIG joints by the welding process have low stability and are not recommended to be applied in those cases requiring high strengths.

\subsection{Testing results of EBW joints}

Similar to Section 3.1, mechanical properties of $30 \mathrm{EBW}$ tensile specimens at five different temperatures are acquired. The results are shown in Tables 6, 7 and 8. Fracture surfaces of all specimens also occurred on the joints.
Table 3

Elongation of TIG joints.

\begin{tabular}{lllllllll}
\hline & \multicolumn{2}{l}{$A(\%)$} \\
\cline { 2 - 8 } Temperature & $A_{1}$ & $A_{2}$ & $A_{3}$ & $A_{4}$ & $A_{5}$ & $A_{6}$ & $\bar{A}$ & $A_{\text {s }}$ \\
\hline $20^{\circ} \mathrm{C}$ & 1.8 & 2 & 3 & 2.5 & 1.5 & 1.6 & 2.1 & 0.6 \\
$100^{\circ} \mathrm{C}$ & 1.9 & 2.5 & 2 & 1.6 & 2.6 & 3.5 & 2.4 & 0.7 \\
$200^{\circ} \mathrm{C}$ & 2.5 & 2 & 1.8 & 3.5 & 2.1 & 1.7 & 2.3 & 0.7 \\
$300^{\circ} \mathrm{C}$ & 1.5 & 3.4 & 2.9 & 2.5 & 2.1 & 2 & 2.4 & 0.7 \\
$400^{\circ} \mathrm{C}$ & 3 & 1.6 & 2.9 & 1.5 & 2.1 & 2.2 & 2.2 & 0.6 \\
\hline
\end{tabular}

Table 4

Tensile strength of TIG joints.

\begin{tabular}{lllllllll}
\hline & \multicolumn{7}{l}{$R_{\mathrm{m}}(\mathrm{MPa})$} \\
\cline { 2 - 8 } Temperature & $R_{\mathrm{m} 1}$ & $R_{\mathrm{m} 2}$ & $R_{\mathrm{m} 3}$ & $R_{\mathrm{m} 4}$ & $R_{\mathrm{m} 5}$ & $R_{\mathrm{m} 6}$ & $\overline{R_{\mathrm{m}}}$ & $R_{\mathrm{ms}}$ \\
\hline $20^{\circ} \mathrm{C}$ & 91.5 & 97.5 & 174.5 & 108 & 136 & 118 & 120.9 & 30.6 \\
$100^{\circ} \mathrm{C}$ & 129 & 83.5 & 139 & 146 & 103.5 & 105 & 117.7 & 24.1 \\
$200^{\circ} \mathrm{C}$ & 93.5 & 161 & 85.5 & 102 & 118 & 105 & 110.8 & 26.9 \\
$300^{\circ} \mathrm{C}$ & 73.5 & 89.5 & 76 & 49 & 86 & 76.5 & 75.1 & 14.2 \\
$400^{\circ} \mathrm{C}$ & 32.5 & 52.5 & 36.5 & 93 & 127 & 39.5 & 63.5 & 38.2 \\
\hline
\end{tabular}

Table 5

Yield strength of TIG joints.

\begin{tabular}{|c|c|c|c|c|c|c|c|c|}
\hline \multirow[b]{2}{*}{ Temperature } & \multicolumn{8}{|c|}{$R_{\mathrm{p}}(\mathrm{MPa})$} \\
\hline & $R_{\mathrm{p} 1}$ & $R_{\mathrm{p} 2}$ & $R_{\mathrm{p} 3}$ & $R_{\mathrm{p} 4}$ & $R_{\mathrm{p} 5}$ & $R_{\mathrm{p} 6}$ & $\overline{R_{\mathrm{p}}}$ & $R_{\mathrm{ps}}$ \\
\hline $20^{\circ} \mathrm{C}$ & 87.5 & 82 & 113.5 & 95 & 101 & 88 & 94.5 & 11.4 \\
\hline $100^{\circ} \mathrm{C}$ & 75 & 75 & 106 & 87 & 97 & 77.5 & 86.3 & 12.9 \\
\hline $200^{\circ} \mathrm{C}$ & 62.5 & 121.5 & 83 & 68 & 90 & 89 & 85.7 & 20.8 \\
\hline $300^{\circ} \mathrm{C}$ & 70 & 80.5 & 55.5 & 43.5 & 85.5 & 74.5 & 68.3 & 15.9 \\
\hline $400^{\circ} \mathrm{C}$ & 31 & 49.5 & 36 & 76 & 94 & 34.5 & 53.5 & 25.8 \\
\hline
\end{tabular}

All EBW joints have yielding with good consistency, demonstrating that EBW joints have better ductility. Tensile strength and yield strength decline as temperature is increased. Meanwhile, tensile strengths and yield strengths vary a little at the same temperature with a maximum difference of $46 \mathrm{MPa}$ and all standard deviations are less than $20 \mathrm{MPa}$, indicating that the EBW joints by the welding process have high stability and will be preferred in practical applications.

\subsection{Welded joints versus bulk CuCrZr}

Mechanical properties of both welded joints are much lower than that of bulk $\mathrm{CuCrZr}$, as shown in Fig. 2. The tensile strength of TIG joints is about $1 / 5$ of the base material and $1 / 3$ for EBW joints. The yield strength of TIG and EBW joints is only $1 / 6$ and $1 / 4$ of the base material, respectively. Elongation of EBW joints is approximately $1 / 5$ of $\mathrm{CuCrZr}$, while that of TIG joints is about $1 / 8$. Changing trends of tensile strength and yield strength of both joints are consistent with that of the base material.

\subsection{Acceptance criteria}

To ensure that the high-heat-load photon absorbers can work safely during a long service period, the failure of vacuum joints due to the excessive thermal stress and strain should be avoided. It is necessary to establish the acceptance criteria 
Table 6

Elongation of EBW joints.

\begin{tabular}{lllllllll}
\hline & \multicolumn{2}{l}{$A(\%)$} \\
\cline { 2 - 8 } Temperature & $A_{7}$ & $A_{8}$ & $A_{9}$ & $A_{10}$ & $A_{11}$ & $A_{12}$ & $\bar{A}$ & $A_{\text {s }}$ \\
\hline $20^{\circ} \mathrm{C}$ & 2.1 & 2.5 & 2.4 & 3 & 2.6 & 2.5 & 2.5 & 0.3 \\
$100^{\circ} \mathrm{C}$ & 3.4 & 3 & 2.5 & 2.6 & 3.1 & 2.5 & 2.9 & 0.4 \\
$200^{\circ} \mathrm{C}$ & 2.8 & 3.5 & 3 & 2.5 & 2.7 & 3.6 & 3.0 & 0.4 \\
$300^{\circ} \mathrm{C}$ & 2.7 & 3 & 3.1 & 3.5 & 3 & 3.3 & 3.1 & 0.3 \\
$400^{\circ} \mathrm{C}$ & 2.5 & 2.4 & 2.9 & 3.4 & 3.1 & 2.6 & 2.8 & 0.4 \\
\hline
\end{tabular}

Table 7

Tensile strength of EBW joints.

\begin{tabular}{llllllllr}
\hline & \multicolumn{7}{l}{$R_{\mathrm{m}}(\mathrm{MPa})$} \\
\cline { 2 - 8 } Temperature & $R_{\mathrm{m} 7}$ & $R_{\mathrm{m} 8}$ & $R_{\mathrm{m} 9}$ & $R_{\mathrm{m} 10}$ & $R_{\mathrm{m} 11}$ & $R_{\mathrm{m} 12}$ & $\overline{R_{\mathrm{m}}}$ & $R_{\mathrm{ms}}$ \\
\hline $20^{\circ} \mathrm{C}$ & 199 & 201 & 219 & 235 & 223 & 243 & 220 & 17.7 \\
$100^{\circ} \mathrm{C}$ & 142 & 178 & 184 & 172 & 188 & 145 & 168.2 & 19.9 \\
$200^{\circ} \mathrm{C}$ & 155 & 139 & 141 & 128 & 129 & 127 & 136.5 & 10.8 \\
$300^{\circ} \mathrm{C}$ & 123 & 136 & 118 & 119 & 135 & 118 & 124.8 & 8.5 \\
$400^{\circ} \mathrm{C}$ & 131 & 106 & 88 & 119 & 98 & 104 & 107.7 & 15.3 \\
\hline
\end{tabular}

Table 8

Yield strength of EBW joints.

\begin{tabular}{lrrrrrrrl}
\hline & \multicolumn{2}{l}{$R_{\mathrm{p}}(\mathrm{MPa})$} \\
\cline { 2 - 8 } Temperature & $R_{\mathrm{p} 7}$ & $R_{\mathrm{p} 8}$ & $R_{\mathrm{p} 9}$ & $R_{\mathrm{p} 10}$ & $R_{\mathrm{p} 11}$ & $R_{\mathrm{p} 12}$ & $\overline{R_{\mathrm{p}}}$ & $R_{\mathrm{ps}}$ \\
\hline $20^{\circ} \mathrm{C}$ & 176 & 156 & 149 & 153 & 152 & 168 & 159 & 10.6 \\
$100^{\circ} \mathrm{C}$ & 125 & 108 & 149 & 115 & 140 & 117 & 126 & 15.8 \\
$200^{\circ} \mathrm{C}$ & 125 & 106 & 86 & 98 & 122 & 115 & 108.7 & 15 \\
$300^{\circ} \mathrm{C}$ & 98 & 88 & 91 & 102 & 122 & 103 & 100.7 & 12.0 \\
$400^{\circ} \mathrm{C}$ & 90 & 94 & 76 & 97 & 85 & 90 & 88.7 & 7.4 \\
\hline
\end{tabular}

when performing finite-element analysis. On the basis of the engineering conservativeness, the temperature on the joints should be no more than $250^{\circ} \mathrm{C}$; thermal stress and strain should be no more than the yield strength and elongation at the temperature (Thomas et al., 2016; Zhang et al., 2002).

From the above testing results, formulas of yield strength and elongation based on the temperature can be obtained by the polynomial fitting method. For TIG joints, that is

$$
\begin{aligned}
& R_{\mathrm{p}-\mathrm{TIG}}=93.5-0.014 T+0.0002 T^{2} \\
& A_{\mathrm{TIG}}=2.08+0.0028 T+0.000006 T^{2} .
\end{aligned}
$$

For EBW joints, that is

$$
\begin{aligned}
& R_{\mathrm{p}-\mathrm{EBW}}=162.9-0.359 T+0.0004 T^{2}, \\
& A_{\mathrm{EBW}}=2.41+0.0056 T+0.000011 T^{2},
\end{aligned}
$$

where $T\left({ }^{\circ} \mathrm{C}\right)$ is the temperature on the joints and should be no more than $250^{\circ}$ C. $R_{\mathrm{p}-\mathrm{TIG}}(\mathrm{MPa})$ is the yield strength of TIG joints on $T, R_{\mathrm{p}-\mathrm{EBW}}(\mathrm{MPa})$ is the yield strength of EBW joints on $T$, and $A_{\text {TIG }}$ and $A_{\mathrm{EBW}}(\%)$ are the elongation of the TIG joints and EBW joints at $T$, respectively.

The temperature, thermal stress and strain thresholds corresponding to both vacuum joints are listed in Table 9.

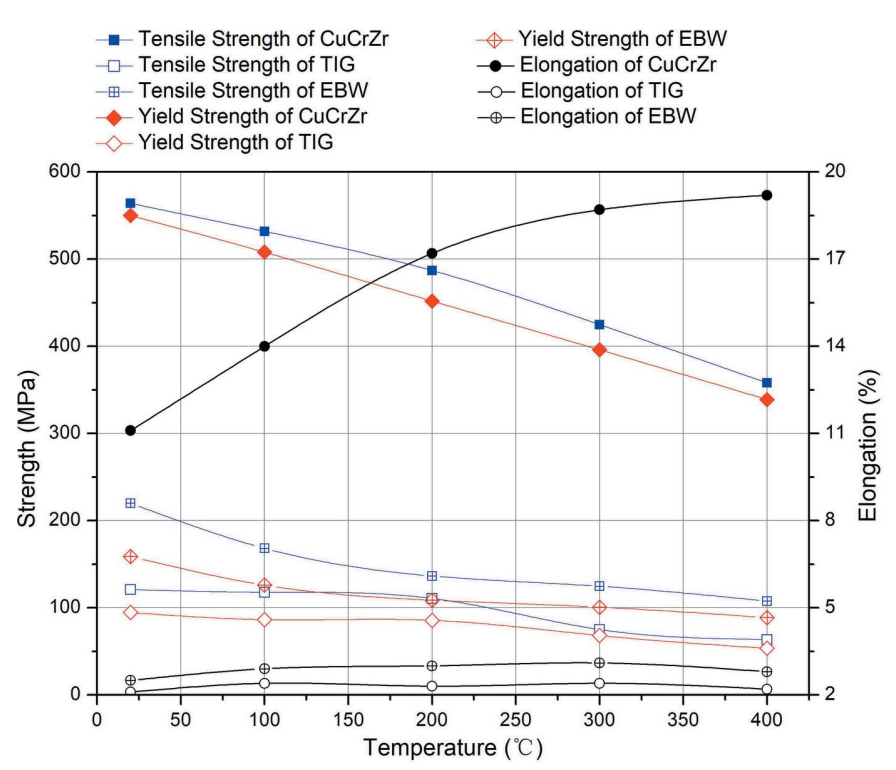

Figure 2

Welded joints versus bulk CuCrZr.

\section{Applications}

A superconducting wiggler, as source of the ultra-hard X-ray applications beamline (BL12SW) in the SSRF Phase-II beamline project, will generate high-energy X-rays up to $150 \mathrm{keV}$ and significantly strengthen the application potential of SSRF. The total radiant heat power received by the frontend of BL12SW is over $44.7 \mathrm{~kW}$, and the peak power density is

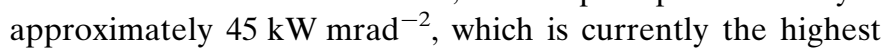
heat load for a front-end at SSRF. The power density distribution of the superconducting wiggler is shown in Fig. 3.

Four photon absorbers made of Glidcop ${ }^{\circledR} \mathrm{AL}-15$ or $\mathrm{CuCrZr}$ are located in sequence to handle this radiation. Fig. 4(a) shows a photon absorber that was utilized in the SSRF Phase-I front-end and has only one absorber with a total length of about $300 \mathrm{~mm}$. The novel photon absorber has two subabsorbers welded to each other by EBW and a total length of

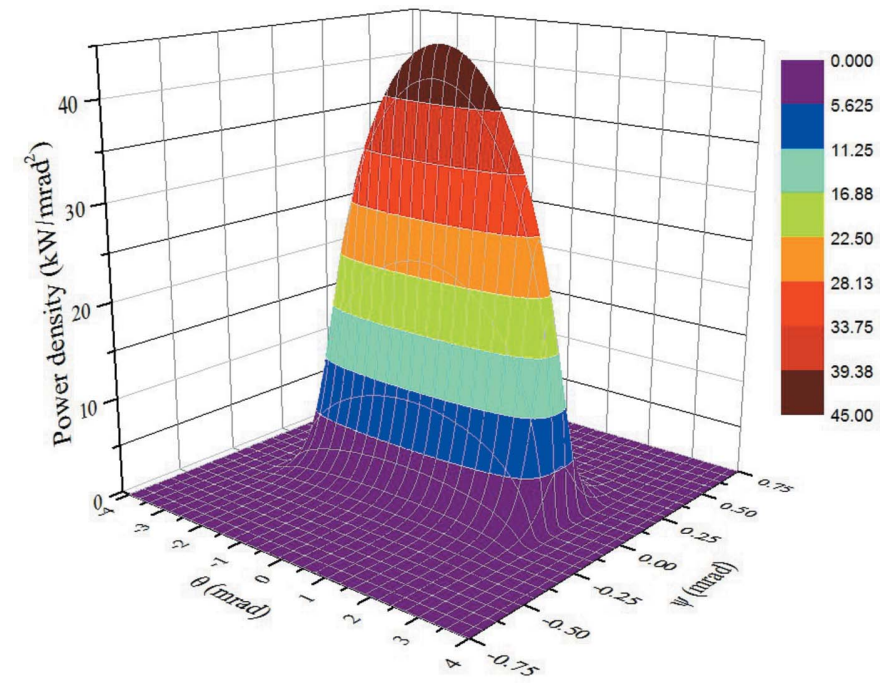

Figure 3

Power density distribution of the superconducting wiggler. 
Table 9

Engineering conservative acceptance criteria of vacuum joints.

\begin{tabular}{llr}
\hline & TIG joint & EBW joint \\
\hline Maximum temperature $\left({ }^{\circ} \mathrm{C}\right)$ & & $\leq 250$ \\
Maximum equivalent stress (MPa) & $\leq 93.5-0.014 T+0.0002 T^{2}$ & $\leq 162.9-0.359 T+0.0004 T^{2}$ \\
Maximum equivalent strain (\%) & $\leq 2.08+0.0028 T+0.000006 T^{2}$ & $\leq 2.41+0.0056 T+0.000011 T^{2}$ \\
\hline
\end{tabular}
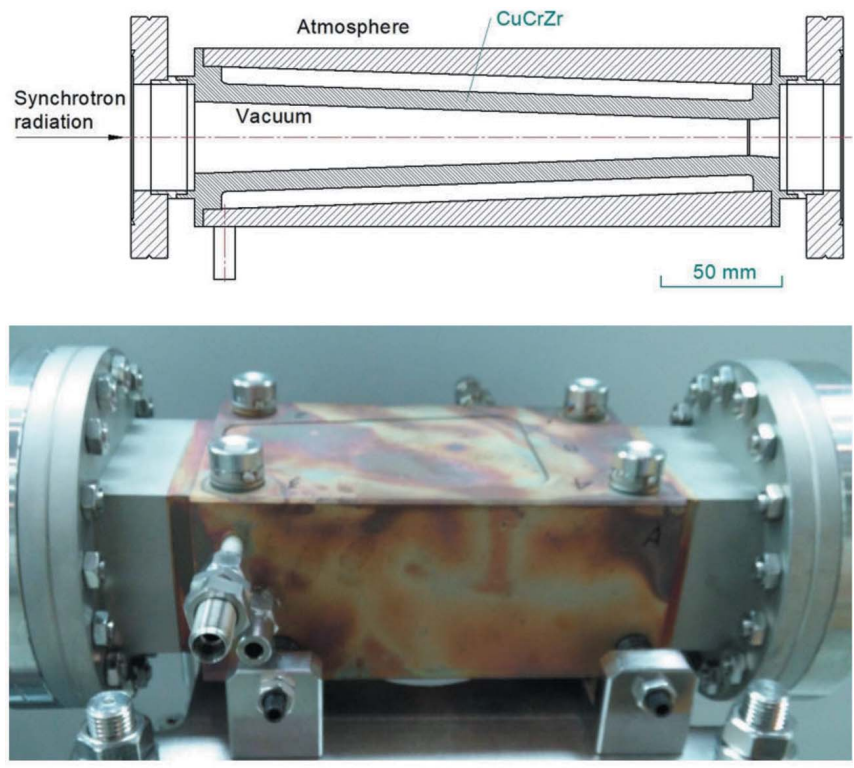

(a)
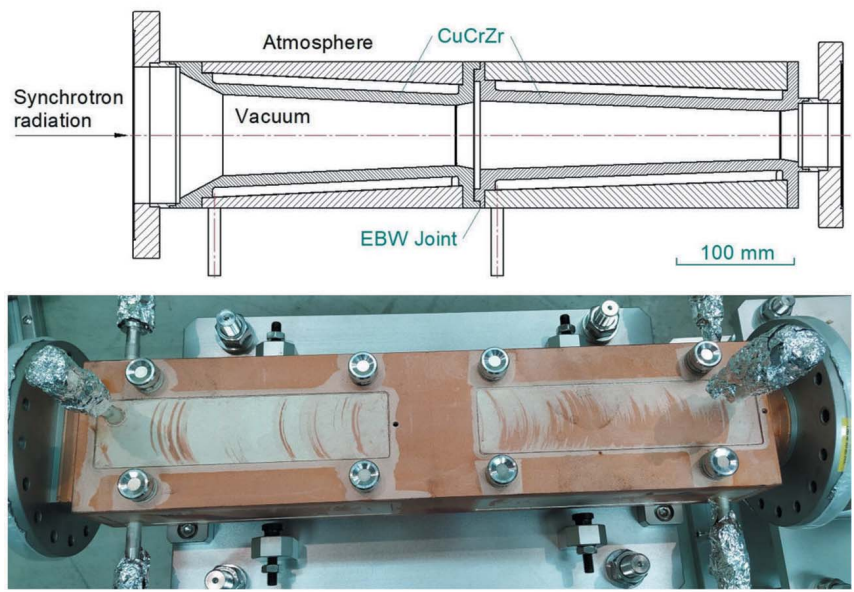

(b)

Figure 4

Usual photon absorber $(a)$ and welded photon absorber $(b)$.

up to $600 \mathrm{~mm}$, as shown in Fig. 4(b). The inside of all the photon absorbers is in ultrahigh-vacuum while the outside is at atmospheric pressure.

Finite-element analysis by ANSYS (Jin et al., 2021; Xu et al., 2015 ) indicates that the maximum temperature on the joint is $78.7^{\circ} \mathrm{C}$, maximum equivalent stress and strain are, respectively, $49.58 \mathrm{MPa}$ and $0.039 \%$, as shown in Fig. 5. The yield strength and elongation of the EBW joint at $78.7^{\circ} \mathrm{C}$ can be calculated from equations (3) and (4) to be $137.1 \mathrm{MPa}$ and $2.92 \%$, respectively. Therefore, the practical maximum temperature,

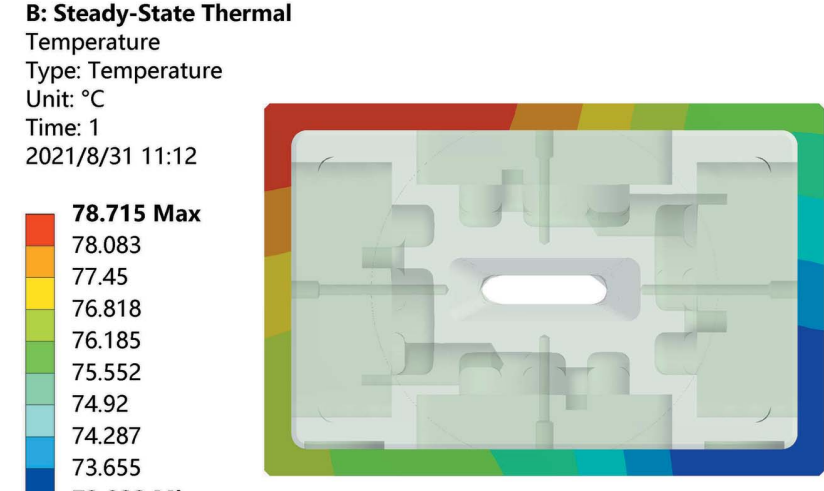

(a)

\section{C: Static Structural}

Equivalent Stress

Type: Equivalent (von-Mises) Stress

Unit: $\mathrm{Pa}$

Time: 1

2021/8/31 11:12

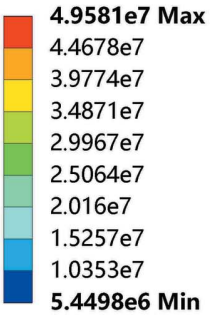

5.4498e6 Min

\section{C: Static Structural}

Equivalent Elastic Strain

Type: Equivalent Elastic Strain

Unit: $\mathrm{m} / \mathrm{m}$

Time: 1

$2021 / 8 / 3111: 12$

\begin{tabular}{|l|}
\hline 0.00038746 \\
0.00035088 \\
0.00031431 \\
0.00027774 \\
0.00024116 \\
0.00020459 \\
0.00016802 \\
0.00013144 \\
$9.4869 \mathrm{e}-5$ \\
\hline
\end{tabular}

Figure 5

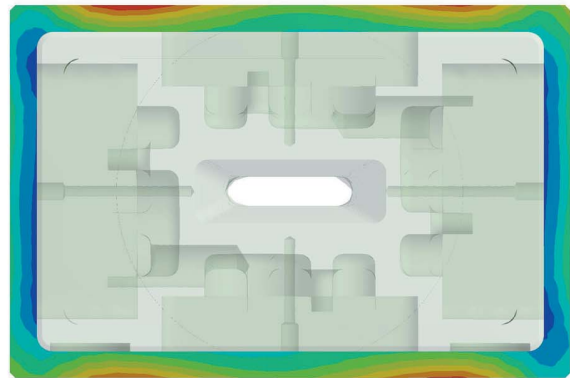

(b)

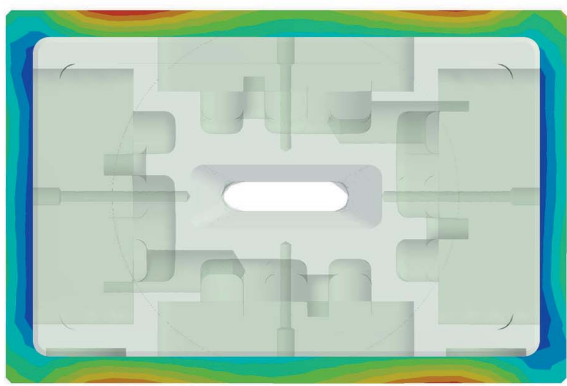

(c)

(a) Temperature, (b) equivalent stress and (c) equivalent strain distributions of the joint.

equivalent stress and strain are only $31.5 \%, 36.2 \%$ and $1.3 \%$, respectively, of the corresponding thresholds, which indicates that the EBW joints will work safely in the highestheat-load front-end in the SSRF Phase-II beamline project. 


\section{Conclusions}

Mechanical properties of TIG joints and EBW joints of $\mathrm{CuCrZr}$ to the same material, which is utilized in the SSRF front-end, are obtained by tensile tests at $20^{\circ} \mathrm{C}, 100^{\circ} \mathrm{C}, 200^{\circ} \mathrm{C}$, $300^{\circ} \mathrm{C}$ and $400^{\circ} \mathrm{C}$. Testing results show that, in comparison with the base material, tensile strength and yield strength of both vacuum joints decline by $2 / 3$ or $4 / 5$ and elongation falls by $4 / 5$ or more. Compared with TIG joints, EBW joints have higher strength, better ductility and more stable performance.

To ensure that the high-heat-load photon absorbers can work safely during a long service period, an engineering conservative acceptance criteria of vacuum joints is created by the polynomial fitting method. A novel welded photon absorber with a total length of $600 \mathrm{~mm}$ has been successfully designed and manufactured. Finite-element analysis by ANSYS shows that the maximum temperature, equivalent stress and strain are only $31.5 \%, 36.2 \%$ and $1.3 \%$, respectively, of the corresponding thresholds.

In practical engineering applications, vacuum joints are subjected to low temperature, low stress and strain as are being kept out of direct high-power synchrotron radiation. Therefore, EBW joints of $\mathrm{CuCrZr}$ entirely satisfy the practical requirements and will be applicable in the highest-heat-load front-end in the SSRF Phase-II beamline project.

\section{Funding information}

The following funding is acknowledged: National Natural Science Foundation of China (award No. 11805262); Youth Innovation Promotion Association, Chinese Academy of Sciences (award No. 2020288).

\section{References}

Edwards, D. J., Singh, B. N. \& Tähtinen, S. (2007). J. Nucl. Mater. 367370, 904-909.

Gillia, O., Briottet, L., Chu, I., Lemoine, P., Rigal, E. \& Peacock, A. (2009). J. Nucl. Mater. 386-388, 830-833.

Glidcop $^{\circledR}$ (2021). North American Höganäs High Alloys LLC, http:// www.hoganas.com/.

Groh, H. C. III de, Ellis, D. L. \& Loewenthal, W. S. (2008). J. Mater. Eng. Perform. 17, 594-606.
He, J. H. \& Zhao, Z. T. (2014). Natl. Sci. Rev. 1, 171-172.

Huang, Y. C., Li, M., Ma, C. Q., Xiao, Z. B. \& Liu, Y. (2019). J. Cent. S. Univ. 26, 1550-1562.

Jin, L. M., Li, Y. J., Zhu, W. Q., Xue, S., Wang, N. X. \& Xu, Z. M. (2021). Nucl. Instrum. Methods Phys. Res. A, 989, 164955.

Manohar, M. S., Rao, Y. R. \& Sandilya, N. (2018). J. Sci. Ind. Res. 77, 533-536.

Nomura, Y., Suzuki, R. \& Saito, M. (2002). J. Nucl. Mater. 307-311, 681-685.

Sahlot, P., Nene, S. S., Frank, M., Mishra, R. S. \& Arora, A. (2018). Sci. Technol. Weld. Joining, 23, 715-720.

Sakurai, Y., Oura, M., Takahashi, S., Hayashi, Y., Aoyagi, H., Shiwaku, H., Kudo, T., Mochizuki, T., Oikawa, Y., Takahasi, M., Yoshii, K. \& Kitamura, H. (1998). J. Synchrotron Rad. 5, 11951198.

Sheng, I. C., Chang, C. C., Chan, C. K., Shueh, C. \& Wu, L. H. (2016). Proceedings of 9th International Workshop on Mechanical Engineering Design of Synchrotron Radiation Equipment and Instrumentation (MEDSI2016), 11-16 September 2016, Barcelona, Spain, pp. 77-79.

Shu, D. M. \& Ramanathan, M. (2002). Rev. Sci. Instrum. 73, 15801582.

Shueh, C., Chan, C. K., Chang, C. C. \& Sheng, I. C. (2017). Nucl. Instrum. Methods Phys. Res. A, 841, 1-4.

Thomas, F., Biasci, J. C., Coulon, D., Dabin, Y., Ducoing, T., Ewald, F., Gagliardini, E. \& Marion, P. (2016). Proceedings of the 9th International Workshop on Mechanical Engineering Design of Synchrotron Radiation Equipment and Instrumentation (MEDSI2016), 11-16 September 2016, Barcelona, Spain, pp. 257261.

Wei, R., Li, Q., Wang, W. J., Wang, J. C., Wang, X. L., Xie, C. Y. \& Luo, G. N. (2018). Fusion Eng. Des. 128, 47-52.

Xu, Z. M., Feng, X. K., Wang, N. X., Wu, G. Y., Zhang, M. \& Wang, J. (2015). Nucl. Instrum. Methods Phys. Res. A, 774, 94-102.

Zeng, L. (1993). Modern Welding Handbook. Shanghai Science and Technology Press.

Zhang, L., Biasci, J. C. \& Plan, B. (2002). Proceedings of the 2nd International Workshop on Mechanical Engineering Design of Synchrotron Radiation Equipment and Instrumentation (MEDSI2002), 5-6 September 2002, Argonne, USA, pp. 377-389.

Zhao, Z. T., Yin, L. X., Leng, Y. B., Zhang, W. Z., Jiang, B. C. \& Tian, S. Q. (2013). Proceedings of the 4th International Particle Accelerator Conference (IPAC2013), 12-17 May 2013, Shanghai, China, pp. 178-180.

Zinkle, S. J. (2016). Phys. Scr. T167, 014004. 